\title{
Avaliação do efeito de doses e fontes de nitrogênio sobre variáveis morfológicas, interceptação de radiação e produtividade do girassol
}

\author{
Felipe Schwerz', Braulio Otomar Caron ${ }^{2}$, Elvis Felipe Elli', Douglas Machado de Oliveiral, \\ Gean Charles Monteirol, Velci Queiróz de Souza ${ }^{2}$
}

$10.1590 / 0034-737 X 201663030015$

\begin{abstract}
RESUMO
Objetivou-se, com este trabalho, avaliar o efeito de doses e de fontes de nitrogênio sobre as variáveis morfológicas relacionadas com a produtividade de dois cultivares de girassol. O delineamento utilizado foi o de blocos ao acaso, em esquema fatorial $5 \times 2 \times 2$, com cinco doses de adubação nitrogenada $\left(0,40,80,120\right.$ e $\left.160 \mathrm{~kg} \mathrm{ha}^{-1}\right)$, duas fontes de nitrogênio (N), fertilizante convencional (ureia), com $44 \%$ de $\mathrm{N}$ e fertilizante nitrogenado de liberação lenta, com $26 \%$ de $\mathrm{N}$, e dois cultivares de girassol (Olisun 3 e Aguará 6), com três repetições. Avaliaram-se altura de plantas, índice de área foliar, interceptação de radiação global, massa de mil aquênios, diâmetro do capítulo, produtividade de aquênios e estimou-se o teor de clorofila. Doses crescentes de $\mathrm{N}$ promovem aumento do índice de área foliar e de interceptação da radiação global, do florescimento pleno e da produtividade do girassol, de forma diferenciada entre cultivares. O fertilizante nitrogenado de liberação lenta possibilita índice de área foliar, no início de enchimento de aquênios, maior que o obtido por uso de ureia, a partir da dose de $120 \mathrm{~kg} \mathrm{ha}^{-1} \mathrm{de} \mathrm{N}$. O cultivar Olisun 3 apresenta maior índice de área foliar no florescimento pleno e maior produtividade, a partir das doses de 80 e de $120 \mathrm{~kg} \mathrm{ha}^{-1} \mathrm{de} \mathrm{N}$, respectivamente.
\end{abstract}

Palavras-chave:área foliar, taxa fotossintética, Helianthus annuиs L.

\section{ABSTRACT \\ Evaluation of the effect of doses and sources of nitrogen on morphological variables, radiation interception and yield of sunflower}

The objective of this study was to evaluate the effect of doses and sources of nitrogen on the morphological variables related to yield of two sunflower cultivars. The design was randomized blocks in a factorial design $5 \times 2 \times 2$, with five doses of nitrogen $\left(0,40,80,120\right.$ and $\left.160 \mathrm{~kg} \mathrm{ha}^{-1}\right)$, two sources of nitrogen $(\mathrm{N})$ - conventional fertilizer (urea), with $44 \% \mathrm{~N}$, and slow-release nitrogen fertilizer, with $26 \% \mathrm{~N}-$, and two sunflower cultivars (Olisun 3 and Aguará 6) with three replications. We evaluated the plant height, leaf area index, global radiation interception, weight of a thousand achenes, achene diameter, yield and the estimate of chlorophyll content. Increasing doses of $\mathrm{N}$ promote an increase in the leaf area index, interception of global radiation, full flowering and sunflower yield, in a different way between cultivars. The use of slow-release nitrogen fertilizer provides higher leaf area index in the beginning of achenes filling, compared to the use of urea, from the dose of $120 \mathrm{Kg} \mathrm{ha}^{-1} \mathrm{~N}$. The cultivar Olisun 3 shows greater leaf area index at full flowering and yield, from the doses of 80 and $120 \mathrm{~kg} \mathrm{ha}^{-1} \mathrm{~N}$, respectively.

Key words: leaf area; photosynthetic rate; Helianthus annuиs L.

Submetido em: 06/01/2015 e aprovado em:29/10/2015.

${ }^{1}$ Universidade Federal de Santa Maria, Centro de Educação Superior Norte do Rio Grande do Sul, Departamento de Ciências Agronômicas e Ambientais, Frederico Westphalen, Rio Grande do Sul, Brasil. felipe_schwerz@hotmail.com; elvisfelipeelli@yahoo.com; douglas.mdo@hotmail.com; gean.monteiro@yahoo.com.br

${ }^{2}$ Universidade Federal de Santa Maria, Centro de Educação Superior Norte do Rio Grande do Sul, Departamento de Ciências Agronômicas e Ambientais, Frederico Westphalen, Rio Grande do Sul, Brasil. otomarcaron@yahoo.com.br; velciq@gmail.com

* Autor para correspondência: felipe_schwerz@ hotmail.com 


\section{INTRODUÇÃO}

O girassol (Helianthus annuus L.) é uma espécie caracterizada por ampla aclimatação, alto teor e qualidade do óleo de suas sementes, sendo uma das culturas de maior potencial para a produção de biocombustível, o que a insere no programa nacional de produção e de uso de biodiesel (Ungaro, 2006). O nitrogênio (N) é um nutriente que altera positivamente a produtividade de aquênios, na cultura do girassol, e o seu manejo adequado torna-se indispensável para o melhor aproveitamento desse elemento.

$\mathrm{O} \mathrm{N}$ desempenha importante função no metabolismo e na nutrição da cultura do girassol, sendo o nutriente que mais limita a sua produção, já que a sua deficiência causa desordens nutricionais e seu excesso ocasiona decréscimo da percentagem de óleo (Biscaro et al., 2008). Sabe-se que o nutriente ocorre em todos os órgãos da planta e as melhores doses de $\mathrm{N}$ podem resultar em melhores condições de crescimento e de desenvolvimento da cultura, como no aumento da área foliar (Fagundes et al., 2007), o que permite $o$ aumento da quantidade de radiação solar interceptada, resultando em aumento da taxa fotossintética.

A produtividade de aquênios do girassol é um caráter complexo, resultante da expressão e da associação de diferentes componentes. Um dos processos mais importantes que determinam a produtividade de uma cultura é a fotossíntese, que depende da interceptação da radiação solar, a qual depende, dentre outros fatores, do índice de área foliar (IAF), (Maldaner et al., 2009). No caso do girassol, ainda há possibilidade de ocorrer o heliotropismo, fenômeno por meio do qual as folhas absorvem luminosidade orientando-se pela trajetória solar, de modo a permanecerem perpendicularmente aos raios solares, melhorando a eficiência de captação de luz (Castro \& Farias, 2005).

Das fontes de nitrogênio disponíveis para aplicação em cobertura, a ureia é o fertilizante mais utilizado no Brasil, sendo que apresenta alta concentração de N, mas acentuadas perdas por volatilização de $\mathrm{NH}_{3}$ e por lixiviação (Civardi et al., 2011). Para minimizar as perdas com a utilização de fertilizantes mais solúveis, como a ureia, verificase a importância deste estudo, que consiste na utilização de fertilizantes nitrogenados de liberação lenta (FNLL). Esses fertilizantes são alternativas interessantes, pois permitem que os nutrientes sejam disponibilizados de maneira gradativa, minimizando os riscos de deficiências nutricionais ou de perdas ao longo do ciclo da cultura.

A partir do pressuposto de que o girassol, quando submetido a diferentes doses de nitrogênio em cobertura, pode apresentar alterações da interceptação de radiação global (IRG), do índice de área foliar (IAF), do teor de clorofila e da altura de plantas, objetivou-se, com este trabalho, avaliar o efeito de doses e de fontes de nitrogênio sobre as variáveis morfológicas relacionadas com a produtividade de dois cultivares de girassol.

\section{MATERIAL E MÉTODOS}

O estudo foi realizado na área experimental do Laboratório de Agroclimatologia, vinculado à Universidade Federal de Santa Maria, campus Frederico Westphalen, RS, com localização geográfica de $27^{\circ} 23^{\prime} 48^{\prime}$ ' S, $53^{\circ} 25^{\prime} 45^{\prime \prime}$ O e altitude de $490 \mathrm{~m}$.

$\mathrm{O}$ solo da área experimental pertence à unidade de mapeamento de Passo Fundo, classificado como Latossolo Vermelho distrófico típico, textura argilosa, profundo e bem drenado (Embrapa, 2006), com a seguinte composição físico-química: $\mathrm{pH}$ em água: 6,0; $\mathrm{P}$ (Mehlich): $3,0 \mathrm{mg} \mathrm{dm}^{-3} ; \mathrm{K}$ : $160 \mathrm{mg} \mathrm{dm}^{-3} ; \mathrm{Ca}: 6,2 \mathrm{cmol}_{\mathrm{c}} \mathrm{dm}^{-3} ; \mathrm{Mg}: 3,3 \mathrm{cmol}_{\mathrm{c}} \mathrm{dm}^{-3} ; \mathrm{Al}: 0,0$ cmol $\mathrm{dm}^{-3}$; CTC: $9,9 \mathrm{cmol}_{\mathrm{c}} \mathrm{dm}^{-3}$; saturação por bases: $76 \%$ e matéria orgânica: $3,1 \%$. Segundo a classificação climática de Köppen, o clima predominante da região é Cfa, caracterizado como subtemperado subúmido. Durante a realização do experimento verificou-se precipitação acumulada de $512,4 \mathrm{~mm}$, com temperatura média variando entre $25,4^{\circ} \mathrm{Ce} 26,6^{\circ} \mathrm{C}$.

O delineamento utilizado foi o de blocos ao acaso, em esquema fatorial $5 \times 2 \times 2$, com cinco doses de adubação nitrogenada $\left(0,40,80,120\right.$ e $\left.160 \mathrm{~kg} \mathrm{ha}^{-1}\right)$, duas fontes de nitrogênio $(\mathrm{N})$, fertilizante convencional (ureia), com $44 \%$ de $\mathrm{N}$, e fertilizante nitrogenado de liberação lenta, com $26 \%$ de N, e dois cultivares de girassol (Olisun 3 e Aguará 6), com três repetições. A semeadura foi realizada manualmente, no dia 24 de janeiro de 2013, a três centímetros de profundidade, com espaçamento de $0,90 \mathrm{~m}$ entre fileiras de plantas e de 0,25 m entre plantas na fileira. A dimensão das parcelas experimentais foi de quatro linhas de três metros de comprimento.

A adubação da área foi realizada com a aplicação de 80 $\mathrm{kg} \mathrm{ha}^{-1} \mathrm{de}$ superfosfato triplo e de $50 \mathrm{~kg} \mathrm{ha}^{-1} \mathrm{de}$ cloreto de potássio. A quantidade total de $\mathrm{P}_{2} \mathrm{O}_{5}$ e $40 \%$ da dose de $\mathrm{K}_{2} \mathrm{O}$ foram aplicados na semeadura, o restante da dose de $\mathrm{K}_{2} \mathrm{O}$ foi aplicado em cobertura, juntamente com a adubação nitrogenada. Em relação à adubação nitrogenada, aplicaram-se $10 \mathrm{~kg} \mathrm{ha}^{-1}$ na semeadura e o restante em cobertura, no estádio V6, sendo que a identificação dos estádios fenológicos foi realizada de acordo com a escala proposta por Castiglioni et al., 1997. Juntamente com a adubação, em cobertura, realizou-se a aplicação da dose de $2 \mathrm{~kg} \mathrm{ha}^{-1}$ de boro (B), tendo como fonte o ácido bórico.

A estimativa do teor de clorofila foi obtida nos estádios R5.5 (SPAD5.5) e R7 (SPAD7) utilizando-se clorofilômetro SPAD-502, sendo realizada a mensuração na última folha completa de cada planta avaliada. Em cada folha de avaliação, selecionavam-se três pontos: zona basal, mediana e axial. Todas as determinações foram realizadas pela manhã.

A radiação global incidente $\left(\mathrm{w} \mathrm{m}^{-2}\right)$ foi determinada nos estádios R5.5 (IRG5.5) e R7 (IRG7), monitorada com 
piranômetro LICOR PY32164, acoplado a um Datalogger (LICOR 1400), sendo determinada no período das 10 às 12h. Os valores de interceptação da radiação global (IRG) foram obtidos com a seguinte equação, proposta por Caron et al. (2012): \% interceptação $=[100-(\operatorname{Rn} \times 100 /$ $\mathrm{Rt}$ )], em que $\mathrm{Rn}=$ radiação global incidente no interior do dossel; $\mathrm{R}_{\mathrm{t}}=$ radiação global total incidente no superior do dossel.

Para a determinação da área foliar, realizou-se a coleta de quatro plantas por parcela, nos estádios R5.5 e R7, (Castiglioni et al., 1997) e em cada planta destacaram-se as folhas do caule e realizou-se a contagem. A área dos limbos foliares foi determinada por método indireto, sendo tomadas as medidas de comprimento (C) e da largura (L) do limbo foliar. O comprimento foi medido ao longo da nervura principal e, a largura, de forma perpendicular à inserção do pecíolo no limbo.

Realizou-se o cálculo da área foliar (AF), conforme metodologia descrita por Ashley et al. (1963): $\mathrm{AF}=\mathrm{C} \times \mathrm{L} \mathrm{x}$ $\mathrm{Nx}$, em que $\mathrm{AF}=$ área foliar, $\mathrm{cm}^{2}$ planta ${ }^{-1} ; \mathrm{C}=$ comprimento médio das folhas, $\mathrm{cm}$ (média de cinco folhas); $\mathrm{L}=$ maior largura da folha, $\mathrm{cm}$ (média de cinco folhas); $\mathrm{N}$ = número de folhas por planta, e $\mathrm{f}=$ fator de correção $-0,5852$ (Aquino et al., 2011).

$\mathrm{O}$ índice de área foliar (IAF) foi determinado nos estádios R5.5 (IAF5.5) e R7 (IAF7), por meio da relação entre a área foliar da planta e a área que ela ocupava no terreno, usando-se seguinte equação: $\mathrm{IAF}=\mathrm{Af} / \mathrm{As}$, em que: $\mathrm{Af}=$ área foliar; As = área de solo.

As variáveis SPAD5.5, SPAD7, IRG5.5, IRG7, IAF5.5 e IAF7 foram determinadas no pleno florescimento dos cultivares e no início de enchimento dos aquênios, ou seja, no estádio R5.5 e R7, respectivamente (Castiglioni et al., 1997). A altura de planta (AP) foi medida no estádio R7, com trena graduada, selecionando-se quatro plantas representativas no centro de cada parcela. A colheita das plantas foi realizada após os aquênios atingirem a maturação (estádio R9), aos 118 dias após a semeadura, quando se coletaram as plantas das duas linhas centrais de cada parcela, excluindo-se as bordas.

No primeiro momento, realizou-se a mensuração do diâmetro do capítulo (DC) com uma fita métrica, após o que se procedeu à trilhagem manual, determinou-se a massa de 1000 aquênios (M1000) e, por fim, obteve-se a produtividade (PROD), quando se determinou a massa dos aquênios e os dados transformados em $\mathrm{kg} \mathrm{ha}^{-1}$, a $13 \%$ de umidade.

Os dados foram submetidos à análise estatística por meio do programa computacional Statistical Analysis System Learning Edition 8.0 (SAS, 2003), em que se realizou a análise de variância, o teste de Tukey $(\mathrm{p}<0,05)$, para os fatores cultivar e fonte, e de regressão, para as doses de N.

\section{RESULTADOS E DISCUSSÃO}

Houve efeito da interação cultivar $\mathrm{x}$ dose sobre as variáveis IAF5.5, IRG5.5 e produtividade. As demais variáveis (SPAD5.5, SPAD7, IRG7, AP, DC e MMA) não mostraram diferença significativa.

Os maiores valores de IAF5.5 foram encontrados com as doses de 80 e de $120 \mathrm{~kg} \mathrm{ha}^{-1}$, para o cultivar Olisun 3. Em relação à IRG5.5 verificou-se a superioridade do cultivar Olisun 3 apenas com a dose de $0 \mathrm{~kg} \mathrm{ha}^{-1}$; com o restante das doses, o cultivar Aguará 6 apresentou-se superior, mesmo não diferindo significativamente (Tabela 1).

Resultados semelhantes foram encontrados por Guedes Filho et al. (2011), trabalhando com doses crescentes de nitrogênio em girassol cv. Embrapa 122/V-2000, relatando que a área foliar apresentou crescimento linear até a dose de $100 \mathrm{~kg} \mathrm{ha}^{-1}$ de N. Fagundes et al. (2007), avaliando o efeito de fontes e doses de nitrogênio no crescimento, desenvolvimento e retardamento da senescência foliar, em girassol cultivado em vasos, observaram incremento da área foliar com o aumento das doses de nitrogênio.

Com relação à produtividade na interação cultivar x dose, pode-se inferir que os cultivares apresentaram diferença significativa com as doses de 40 e de $120 \mathrm{~kg} \mathrm{ha}^{-1} \mathrm{de} \mathrm{N}$, sendo o cultivar Olisun 3 o mais produtivo. Esses resultados estão relacionados com o maior IAF obtido pelo cultivar Olisun 3, uma vez que o aumento da área foliar proporciona o incremento da taxa fotossintética, possibilitando assim o acréscimo do potencial produtivo do cultivar.

Segundo Gazzola et al. (2012), o girassol atinge área foliar máxima na antese, com influência direta na produção final de aquênios, sendo esta reduzida se, por exemplo, na fase da iniciação floral ocorrer redução do número de folhas produzidas, diminuindo assim o potencial produtivo da cultura.

Na interação entre fontes e doses de nitrogênio, o IAF7 foi influenciado pelo fertilizante nitrogenado de liberação lenta, resultando em valores superiores aos obtidos com a aplicação de ureia, a partir das doses de $120 \mathrm{~kg} \mathrm{ha}^{-1}$. Isso pode ser explicado pelo efeito proporcionado pelo fertilizante às plantas, pelo qual a liberação do $\mathrm{N}$ ocorre de forma gradual, permitindo maior disponibilidade do nutriente na fase de início de enchimento de grãos (R7), resultando assim em incremento do IAF.

A duração da área foliar depende, para sustentar o enchimento de grãos após o período de floração, da disponibilidade de fotoassimilados. Quanto maior a área foliar ativa e maior o tempo que esta persistir, desde a floração até a maturação fisiológica, maior o potencial produtivo da cultura (Westgate et al., 1997). Conforme relatos de Mundstock \& Zagonel (1994), o girassol responde à maior disponibilidade de nitrogênio no solo, aumentando a área foliar. 
Na interação cultivar x fonte, constatou-se que os cultivares apresentaram diferença significativa em relação à IRG5.5, quando submetidos à aplicação de ureia, sendo que o cultivar Aguará 6 apresentou maiores valores. Já o cultivar Olisun 3, para o qual o efeito do fertilizante nitrogenado de liberação lenta foi superior ao da ureia.

A interceptação da radiação solar não depende apenas do IAF, mas também de um conjunto de fatores, como tamanho e ângulo da folha, número de folhas, condições meteorológicas e práticas de manejo, destacando-se a adubação nitrogenada. Radin et al. (2003), trabalhando com a cultura do tomateiro, observaram que a absorção, pela cultura, da radiação incidente, depende do seu IAF, da posição solar, da geometria e do tamanho da folha, do ângulo da folha, do arranjo de plantas e das condições meteorológicas. Tanto para o girassol quanto para as demais culturas, a interceptação da radiação global tem elevada importância para a produtividade, visto que afeta diretamente a quantidade de carboidratos resultantes da fotossíntese, além de que outros processos relacionados com a planta e com o ambiente dependem dessa variável (Heldwein et al., 2012).
O cultivar Olisun 3 apresentou, quando submetido à aplicação do fertilizante nitrogenado de liberação lenta, produtividades maiores do que com ureia. Já o cultivar Aguará 6 apresentou seus maiores valores de produtividade quando recebeu aplicação de ureia. Essas características podem ser atribuídas ao efeito genético de cada cultivar, pois a exigência nutricional pode ser variável entre cultivares da mesma espécie, sendo comum observar produtividade diferenciada sob as mesmas condições de adubação nitrogenada, para o mesmo ano agrícola (Santos et al., 2002). Com relação à diferença entre as respostas dos cultivares, quando submetidos à mesma fonte, somente ocorreu diferença com o uso do fertilizante nitrogenado de liberação lenta, quando o cultivar Olisun 3 apresentou os maiores resultados.

O valor médio de IAF5.5 do cultivar Aguará 6 foi de 2,65 , considerado dentro da faixa ideal para a cultura do girassol (Figura 1). Para Castro \& Farias (2005), o IAF ideal, na floração (R5.5), para a cultura do girassol, deve estar entre 2,5 e 3,0. Valores de IAF próximos a esses foram alcançados por Braz \& Rosseto (2009), que, trabalhando com crescimento de plantas de girassol, encontraram índi-

Tabela 1: Desdobramentos das interações entre cultivares de girassol, fonte nitrogenada (ureia e FNLL-Fertilizante nitrogenado de liberação lenta) e doses de nitrogênio, para o índice de área foliar (IAF), interceptação da radiação global (IRG) e produtividade (PROD)

\begin{tabular}{|c|c|c|c|c|c|c|}
\hline \multicolumn{7}{|c|}{ Interação cultivar $x$ dose } \\
\hline \multirow{2}{*}{ Variável } & \multirow{2}{*}{ Cultivar } & \multicolumn{5}{|c|}{ Dose de Nitrogênio $\left(\mathrm{kg} \mathrm{ha}^{-1}\right)$} \\
\hline & & $\mathbf{0}$ & 40 & 80 & 120 & 160 \\
\hline \multirow[t]{2}{*}{ IAF 5.5} & Olisun 3 & $2,49 \mathrm{a}$ & $2,99 \mathrm{a}$ & $4,45 \mathrm{a}$ & $4,52 \mathrm{a}$ & $3,05 \mathrm{a}$ \\
\hline & Aguará 6 & $2,16 \mathrm{a}$ & $2,80 \mathrm{a}$ & $2,82 \mathrm{~b}$ & $2,60 \mathrm{~b}$ & $2,73 \mathrm{a}$ \\
\hline \multirow[t]{2}{*}{ IRG $5.5(\%)$} & Olisun 3 & $85,80 \mathrm{a}$ & $87,23 \mathrm{a}$ & 88,11 a & 86,69 a & 86,94 a \\
\hline & Aguará 6 & $84,31 \mathrm{~b}$ & 88,44 a & $89,30 \mathrm{a}$ & 87,95 a & 87,79 a \\
\hline \multirow[t]{2}{*}{$\operatorname{PROD}\left(\mathrm{kg} \mathrm{ha}^{-1}\right)$} & Olisun 3 & $1711,50 \mathrm{a}$ & 1970,07 a & 1968,67 a & 2494,95 a & 2192,62 a \\
\hline & Aguará 6 & 1751,89 a & $1751,31 \mathrm{~b}$ & $1959,45 \mathrm{a}$ & $1906,52 \mathrm{~b}$ & $2120,23 \mathrm{a}$ \\
\hline \multicolumn{7}{|c|}{ Interação fonte $x$ dose } \\
\hline \multirow{2}{*}{ Variável } & \multirow{2}{*}{ Fonte } & \multicolumn{5}{|c|}{ Dose de Nitrogênio $\left(\mathrm{kg} \mathrm{ha}^{-1}\right)$} \\
\hline & & $\mathbf{0}$ & 40 & 80 & 120 & 160 \\
\hline \multirow[t]{2}{*}{ IAF 7} & Ureia & $2,04 \mathrm{a}$ & $2,71 \mathrm{a}$ & $3,50 \mathrm{a}$ & $2,27 \mathrm{~b}$ & $2,54 \mathrm{~b}$ \\
\hline & FNLL & $1,94 \mathrm{a}$ & $3,09 \mathrm{a}$ & $3,13 \mathrm{a}$ & $3,80 \mathrm{a}$ & $3,73 \mathrm{a}$ \\
\hline \multirow[t]{2}{*}{ IRG $5.5(\%)$} & Ureia & $83,98 \mathrm{a}$ & 88,26 a & $88,93 \mathrm{a}$ & 89,06 a & $86,86 \mathrm{a}$ \\
\hline & FNLL & 82,77 a & 86,5 a & 88,81 a & 88,31 a & 86,98 a \\
\hline \multicolumn{7}{|c|}{ Interação cultivar $\mathbf{x}$ fonte } \\
\hline \multirow{2}{*}{ Variável } & & \multirow{2}{*}{ Cultivar } & \multicolumn{4}{|c|}{ Fonte } \\
\hline & & & & Ureia & \multicolumn{2}{|c|}{ FNLL } \\
\hline \multirow[t]{2}{*}{ IRG $5.5(\%)$} & & \multicolumn{2}{|l|}{ Olisun 3} & $86,38 \mathrm{bB}$ & \multicolumn{2}{|c|}{$87,49 \mathrm{aA}$} \\
\hline & & \multicolumn{2}{|l|}{ Aguará 6} & $87,86 \mathrm{aA}$ & \multicolumn{2}{|c|}{$87,26 \mathrm{aA}$} \\
\hline \multirow[t]{2}{*}{$\operatorname{PROD}\left(\mathrm{kg} \mathrm{ha}^{-1}\right)$} & & \multirow{2}{*}{\multicolumn{2}{|c|}{$\begin{array}{l}\text { Olisun } 3 \\
\text { Aguará } 6\end{array}$}} & $1999,67 \mathrm{aB}$ & \multicolumn{2}{|c|}{$2094,62 \mathrm{aA}$} \\
\hline & & & & $1977,37 \mathrm{aA}$ & & \\
\hline
\end{tabular}

Médias seguidas pela mesma letra minúscula na coluna e maiúscila nas linhas, não diferem entre si pelo teste de Tukey, a 5\% de probabilidade de erro. 
ce de área foliar de 2,39, por ocasião de $100 \%$ do florescimento.

O IAF5.5 do cultivar Olisun 3 apresentou resposta quadrática da curva de resposta, sendo que o máximo foi obtido com a dose de $100 \mathrm{~kg} \mathrm{ha}^{-1}$ de N $(4,52)$, situando-se acima da faixa considerada ideal, que é de 2,5 a 3 , conforme Castro \& Farias (2005). Sabe-se que, a partir de um determinado nível de expansão foliar, a interceptação de radiação mantém-se estável, mesmo aumentando-se o índice de área foliar, o que pode explicar a estabilidade da produção de muitas culturas, mesmo com o aumento da dose de nitrogênio.

Na análise quantitativa, a IRG5.5 apresentou resposta quadrática, para o cultivar Aguará 6, frente ao aumento das doses de N. Observa-se acréscimo da interceptação da radiação, para a qual os maiores valores encontram-se com a dose de $100 \mathrm{~kg} \mathrm{ha}^{-1}$ de $\mathrm{N}$, sendo que doses acima desta provocaram diminuição da IRG5.5. Isso ocorre por causa do autossombreamento, até atingir o IAF crítico,
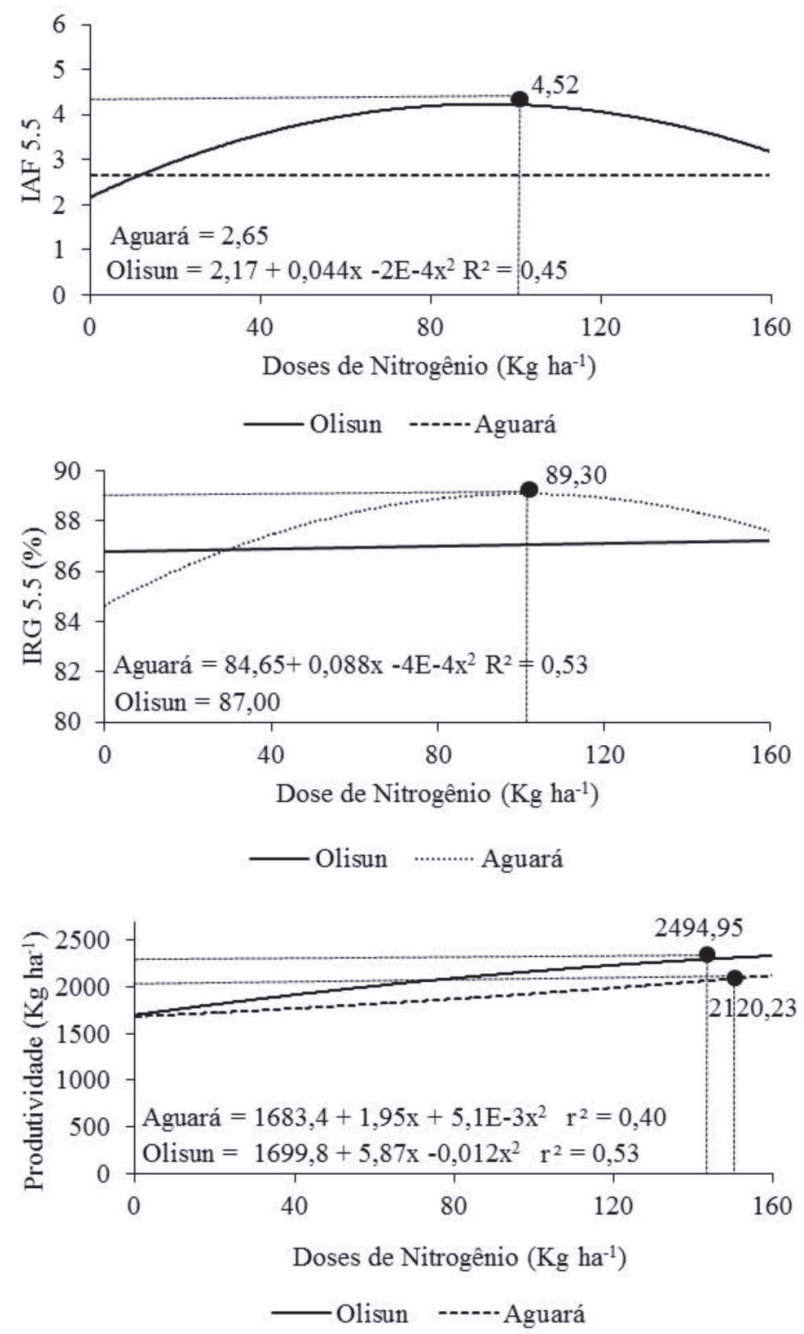

Figura 1: Equações de regressão para interceptação da radiação global (IRG 5.5), índice de área foliar (IAF 5.5) e produtividade de dois cultivares de girassol, em função das doses de nitrogênio, independentemente da fonte nitrogenada utilizada. quando novas áreas foliares não resultam em aumento da quantidade de luz interceptada. Com o aumento do IAF até um valor crítico, também se aumenta a interceptação de luz e, consequentemente, a fotossíntese líquida. O "IAF crítico" é definido como a quantidade de folha requerida para interceptação de $95 \%$ da radiação solar, ao meio dia (Müler, 1981).

A produtividade foi influenciada pelo aumento das doses de $\mathrm{N}$, respondendo positivamente ao acréscimo dos níveis deste elemento, atingindo valores máximos com 132 $\mathrm{kg} \mathrm{ha}^{-1}$ de N, com rendimento de $2495 \mathrm{~kg} \mathrm{ha}^{-1}$ de aquênios, para o cultivar Olisun 3. Zagonel \& Mundstock (1991) verificaram produtividade máxima de aquênios com a dose de $80 \mathrm{~kg} \mathrm{ha}^{-1}$ de $\mathrm{N}$, com rendimento de $2125 \mathrm{~kg} \mathrm{ha}^{-1}$. Da mesma forma, Biscaro et al. (2008) relatam produtividade máxima com a dose de $51,7 \mathrm{~kg} \mathrm{ha}^{-1} \mathrm{de} \mathrm{N}$, com rendimento de $2101 \mathrm{~kg} \mathrm{ha}^{-1}$ de aquênios.

Ao analisar a influência das doses de N no IAF7 (Figura 2), ambas as curvas do gráfico (fontes de ureia e fertilizante nitrogenado de liberação lenta) permitiram o ajuste de uma equação quadrática. O IAF7 aumentou até a dose de $75 \mathrm{~kg} \mathrm{ha}^{-1}$ de N, quando submetida à aplicação de ureia. Em relação à aplicação de FNLL, verifica-se um incremento do IAF7 com o aumento das doses de N. Esse resultado pode ser explicado pelo fato de que a aplicação de altas doses desse fertilizante de liberação lenta possibilita que o nitrogênio permaneça maior tempo disponível às plantas, pois o N é liberado de forma gradual, possibilitando o incremento da área foliar.
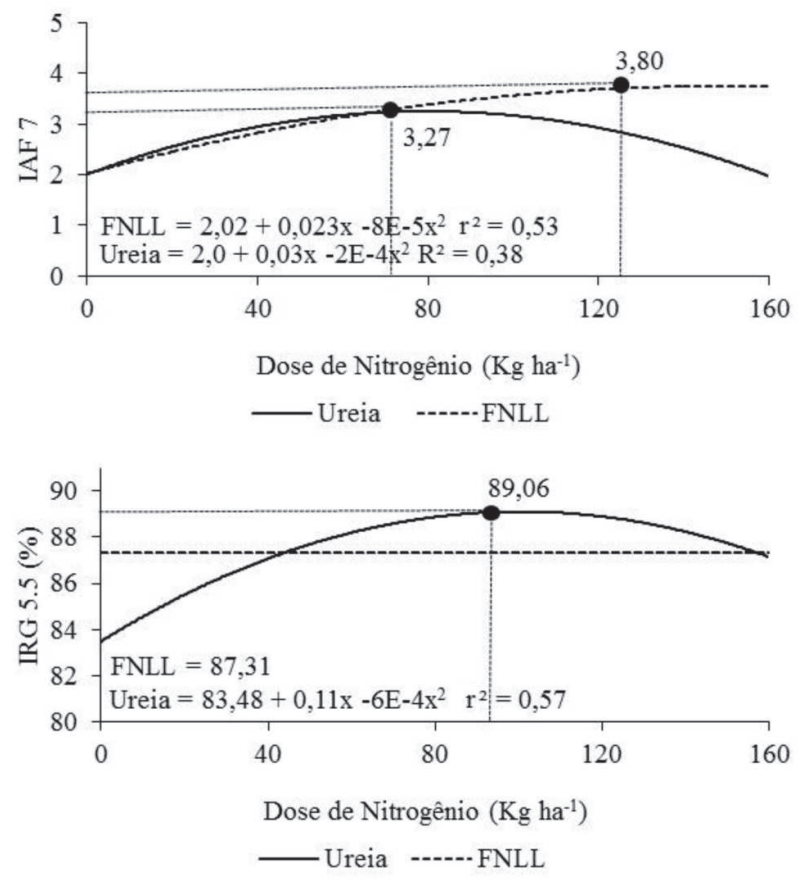

Figura 2: Equações de regressão para índice de área foliar (IAF 7) e interceptação da radiação global (IRG 5.5), de duas fontes nitrogenadas (ureia e FNLL - Fertilizante nitrogenado de liberação lenta), em função das doses de nitrogênio. 
No entanto, a aplicação de altas doses de ureia, acima de $75 \mathrm{~kg} \mathrm{ha}^{-1}$, não resultou em acréscimo de área foliar; isso pode ser atribuído ao fato de $\mathrm{N}$ aplicado permanecer menor tempo disponível para as plantas, pois apresenta alta solubilidade. De acordo com Bono et al. (2008), o baixo aproveitamento do $\mathrm{N}$ pelas plantas pode estar relacionado com os processos de transformação e de perdas no solo, como os de imobilização, desnitrificação, lixiviação e volatilização.

As doses crescentes de $\mathrm{N}$ na forma de ureia possibilitaram um ajuste quadrático da curva de interceptação da radiação global, obtendo-se os maiores valores com a dose de $93 \mathrm{~kg} \mathrm{ha}^{-1}$ de N. Estes resultados estão de acordo com os encontrados por Biscaro et al. (2008), em que observaram maior número de folhas por planta frente aplicação de $80 \mathrm{~kg} \mathrm{ha}^{-1}$ de ureia, sendo que a maior emissão de folhas possibilitou maior interceptação da radiação pelas plantas. De acordo com Fagundes et al. (2007), a aplicação de $100 \mathrm{mg} \mathrm{L}^{-1} \mathrm{de}$ ureia possibilitou maior área foliar, por meio do maior tamanho das folhas, interferindo positivamente na interceptação da radiação pelas plantas.

De modo geral, pode-se inferir que a produtividade aumentou com o acréscimo das doses de $\mathrm{N}$, sendo que o fator determinante, que possibilitou o aumento da produtividade foi a maior área foliar disponível, proporcionando maior interceptação da radiação incidente, resultando, assim, em acréscimo da taxa fotossintética. A aplicação do fertilizante nitrogenado de liberação lenta proporcionou maior IAF no estádio de início de enchimento de grãos, isso por causa da liberação gradual do $\mathrm{N}$, proporcionada por esse produto, resultando na disponibilidade do nutriente por um maior período de tempo.

\section{CONCLUSÕES}

Doses crescentes de $\mathrm{N}$ promovem aumento do índice de área foliar e da interceptação da radiação global no florescimento pleno e da produtividade do girassol, de forma diferenciada entre cultivares.

O fertilizante nitrogenado de liberação lenta possibilita índice de área foliar no início de enchimento de aquênios, maior do que o obtido com ureia, a partir da dose de $120 \mathrm{~kg}$ ha $^{-1}$ de N.

O cultivar Olisun 3 apresenta maior índice de área foliar no florescimento pleno e maior produtividade, a partir das doses de 80 e de $120 \mathrm{~kg} \mathrm{ha}^{-1}$ de $\mathrm{N}$, respectivamente.

\section{REFERÊNCIAS}

Aquino LA, Santos Júnior VC, Guerra JVS \& Costa MM (2011) Estimativa da área foliar do girassol por método não destrutivo. Bragantia, 70:832-836.

Ashley DA, Doss BD \& Bennett OL (1963) A method of determining leaf area in cotton. Agronomy Journal, 55:584-585.
Biscaro GA, Machado JR, Tosta M, Mendonça V, Soratto RP \& Carvalho LA (2008) Adubação nitrogenada em cobertura no girassol irrigado nas condições de Cassilândia-MS. Ciência e Agrotecnologia, 32:1366-1373.

Bono JAM, Rodrigues APDC, Mauad M, Setti JCA, Yanamoto C, Chermouth KS \& Freitas ME (2008) Modo de aplicação de fertilizantes nitrogenados na qualidade fisiológica de sementes de milho. Agrarian, 1:91-102.

Braz MRS \& Rossetto CAV (2009) Crescimento de plantas de girassol em função do vigor de aquênios e da densidade de semeadura. Ciência Rural, 39:1989-1996.

Caron BO, Souza VQ, Costa EC, Eloy E, Behling A \& Trevisan R (2012) Interceptação da radiação luminosa pelo dossel de espécies florestais e sua relação com o manejo das plantas daninhas. Ciência Rural, 42:75-82.

Castiglioni VBR, Balla A, Castro C \& Silveira JM (1997) Fases de desenvolvimento da planta de girassol. Londrina, Embrapa Cnpso. 24p.

Castro C \& Farias JRB (2005) Ecofisiologia do girassol. In: Leite RMVL de C, Brighenti AM \& Casto C (Eds.) Girassol no Brasil. Londrina, Embrapa Cnpso. p.163-218.

Civardi EA, Silveira Neto NA, Ragagnin VA, Godoy ER \& Brod E (2011) Ureia de liberação lenta aplicada superficialmente e ureia comum incorporada ao solo no rendimento do milho. Revista Agropecuária Tropical, 41:52-59.

Embrapa - Empresa Brasileira de Pesquisa Agropecuária (2006) Sistema Brasileiro de Classificação de Solos. $2^{\mathrm{a}}$ ed. Rio de Janeiro, Embrapa São Paulo. 412p.

Fagundes JD, Santiago G, Mello AM, Bellé RA \& Streck NA (2007) Crescimento, desenvolvimento e retardamento da senescência foliar em girassol de vaso (Helianthus annuus L.): fontes e doses de nitrogênio. Ciência Rural, 37:987-993.

Gazzola A, Ferreira JR, Cunha DA, Bortolini E, Paiao GD, Primiano IV, Pestana J, Andrea MSC, Oliveira MS \& Camara GMS (2012) A Cultura do Girassol. Piracicaba, ESALQ/USP/ LPV. 69p. (Apostila Didática).

Guedes filho DH, Chaves LHG, Campos VB, Santos júnior JA \& Oliveira JTL (2011) Production of sunflower and biomass depending on available soil water and nitrogen levels. Iranica Journal of Energy \& Environment, 4:313-319.

Heldwein AB, Maldaner IC, Radons SZ, Loose LH, Lucas DDP \& Hinnah FD (2012) Estimativa do saldo de radiação em girassol como função da radiação solar global. Revista Brasileira de Engenharia Agrícola e Ambiental, 16:194-199.

Maldaner IC, Heldwein AB, Loose LH, Lucas DDP, Guse FI \& Bertoluzzi MP (2009) Modelos de determinação não-destrutiva da área foliar em girassol. Ciência Rural, 39:1356-1361.

Müler L (1981) Fisiologia. In: Myasaka S \& Medina JL (Eds.) A soja no Brasil. Campinas, ITAL. p.109-129.

Mundstock CM \& Zagonel J (1994) Perfil de área foliar de duas cultivares de girassol sob doses e épocas de aplicação de nitrogênio em cobertura. Pesquisa Agropecuária Brasileira, 29:847851 .

Radin B, Bergamaschi H, Reisser JC, Barni NA, Matzenauer R \& Didone I (2003) Eficiência de uso da radiação fotossinteticamente ativa pela cultura do tomateiro em diferentes ambientes. Pesquisa Agropecuária Brasileira, 9:1017-1023.

Santos AC, Andrade AP, Lima JRS, Silva IF \& Cavalcante VA (2002) Variabilidade temporal da precipitação pluvial: nível de nitrogênio no solo e produtividade de cultivares de girassol. Ciência Rural, 32:757-764. 
SAS Learning Edition (2003) Getting started with the SAS Learning Edition. Cary, NC. 200p.

Ungaro MRG (2006) Potencial da cultura do girassol como fonte de matéria prima para o Programa Nacional de Produção e Uso do Biodiesel. In: Câmara GMS \& Heiffig LS (Eds.) Agronegócio de Plantas Oleaginosas: Matérias-primas para o Biodiesel. Piracicaba, ESALQ/USP/LPV. p.57-80.
Westgate ME, Forcella F, Reicosky DD \& Somsen J (1997) Rapid canopy closure for maize production in the northern US corn belt: radiation-use efficiency and grain yield. Field Crops Research, 2:249-258.

Zagonel J \& Mundstock CM (1991) Doses e época de aplicação de nitrogênio em cobertura em duas cultivares de girassol. Pesquisa Agropecuária Brasileira, 26:1487-1492. 